\title{
An Investigation of Optimum Cutting Conditions in Face Milling Nodular Cast Iron FCD 400 Using Carbide Tool
}

\author{
Surasit Rawangwong, Jaknarin Chatthong, Julaluk Rodjananugoon, Romadorn Burapa, \\ and Worapong Boonchouytan
}

\begin{abstract}
The purpose of this research was to investigate the effect of main factors on the surface roughness in nodular cast iron FCD 400 face milling by carbide tool. The results obtained from the analysis which used in the automotive industry, manufacture of molds and other parts of the industries. The etching experiments using semi-automated milling machine Obraeci Strojie brand FGV 32 model. Concerned the material was nodular cast iron FCD 400 using inserts carbide tool. The factors study used a speed, feed rate and depth of cut. Preliminary experiments showed that the depth of cut does not affect the surface roughness fix depth of cut at $2 \mathrm{~mm}$. The experiment illustrated that the factor affecting surface roughness was feed rate and cutting speed with tendency for reduction of roughness value at lower feed rate and greater cutting speed, it was possible determine a facing condition by means of the equation $\mathrm{Ra}=1.07-0.000655$ speed $+\mathbf{0 . 0 0 0 5 6 2}$ feed rate leading this equation goes to use is in limitation speed $500-1,000 \mathrm{rpm}$. at feed rate $160-315 \mathrm{~mm} / \mathrm{min}$. From the experiment is to confirm the result of a comparison between the equation and the action value. The result from the experiment of mean absolute percentage error of the equation of surface roughness is $3.50 \%$ which is less than the margin of error and is acceptable.
\end{abstract}

Index Terms-Milling machine, nodular cast iron, face milling, surface roughness, carbide tool.

\section{INTRODUCTION}

Nodular cast iron is becoming popular for many engineering applications on account of its potential advantages i.e. having high strength and toughness, good fatigue, and wear resistance. Due to the metallurgical nature of these materials, the machining of these materials with the conventional machining techniques such as milling and turning are problematic and difficult [1]. Nodular cast iron FCD 400 is widely used in automotive industry such as for fuel pump and oil pump, engine cylinder and cranks shaft. This material has a great potential due to good mechanical property, easy to cast and cheap. Carbide tool is important in machining application due to availability and cheap as compared to other cutting tool material.

Surface roughness is an important measure of product quality since it greatly influences the performance of mechanical parts as well as production cost. There have been many research developments in modeling surface roughness

Manuscript received Januray 1, 2013; revised March 18, 2013.

The authors were with Rajamangala University of Technology Srivijaya, Songkhla, CO 90000 Thailand (e-mail: sitnong2@yahoo.co.th, jaknarin.c@hotmail.com, romadorn.b@hotmail.com, b_ieeng@hotmail.com). and optimization of the controlling parameters to obtain a surface finish of desired level since only proper selection of cutting parameters can produce a better surface finish. In the manufacturing industries, various machining processes are adapted for removing the material from the workpiece for a better product. Out of these, end milling process is one of the most vital and common metal cutting operations used for machining parts because of its ability to remove materials faster with a reasonably good surface quality.

A brief review of literature on surface roughness modeling in milling is presented here. Surface roughness and dimensional accuracy have been important factors in predicting the machining performances of any machining operation. Considered three different materials, viz., $6061 \mathrm{Al}$, $7075 \mathrm{Al}$ and ANSI 4140 steel for roughness study in CNC milling [2]. Used Taguchi design to consider prediction of surface roughness in CNC face milling of Aluminum alloy [3]. Investigated surface roughness in slot end milling of Aluminum [4]. Investigated the influence of micro-end-milling cutting conditions on roughness of a brass surface using response surface method [5]. Application of response surface methodology in the optimization of cutting conditions for surface roughness [6]. Developed a mathematical model for surface roughness considering the cutting parameters and tool geometry during end milling of medium carbon steel using response surface method [7]. Recently, The statistical modeling of surface roughness in high speed flat end milling [8]. Used the Taguchi optimization method for low surface roughness value in terms of cutting parameters in CNC face milling of Cobalt based alloy [9]. Moreover, to presented the optimization of cutting parameters for side milling of medium carbon steel with multiple roughness characteristics, viz., feeding direction roughness, axial direction roughness and waviness using grey relational Taguchi approach [10].

This paper will presents the in investigating any proper condition in face milling of nodular cast iron FCD 400 in terms of surface roughness and tool wear of the cutting tool.

\section{EQUiPMENT AND TOOLS}

This research study aimed to investigate the effect of main factors on the surface roughness in nodular cast iron FCD 400 face milling process by semi-automaticed milling machine and using carbide tools. The following equipment and instrument were used. 
1) Semi milling machine of model Obraeci Strojie type FGV 32 with technical specifications including a speed rate 45-2,000 rpm, feed rate 14-900 $\mathrm{mm} / \mathrm{min}$.

2) Workpiece Samples: Nodular cast iron FCD 400 with $50 \times 250 \mathrm{~mm}$ in a cross section and $300 \mathrm{~mm}$ in a length.

3) Cutting tools: Carbide inserts model Iscar type SEKT 1204AFR-HM. Fine type carbide tool.

4) Tool holder: Fine type carbide tool with 63 millimeter diameter of 5 edges.

5) A surface roughness measuring device of model Mitutoyo Surftest SJ-201.

\section{Methodology}

There were four main procedures that served the purposes of conducting this research study. First, it was to investigate the sample size for designing the nodular cast iron FCD 400 by milling machine. Second, it was to study the factors expected to make an effect on surface roughness in the nodular cast iron FCD 400 face milling process. Third, it was a pilot treatment to examine the optimum surface roughness and the last, procedure was to take the real treatment in order to confirm the results. These were detailed in the following.

Procedures no. 1 To investigate the sample size for designing the nodular cast iron FCD 400 milling machine by using Minitab R.15 with statistic reliability and significance at $95 \%$ and $5 \%$ respectively

Procedures no. 2 To study the factors affecting surface roughness in the nodular cast iron FCD 400 face milling process by using completely randomized factorial designs with 5 repeated treatments for reducing the variation of sampling. Minitab R.15 was employed to calculate statistic values and to analyze the $2^{3}$ factorial design, [11]-[13]. The 3 factors and the responsive surface roughness value, as shown in Table I.

TABLE I: THE ALlOCATED VARIATION IN PROCEDURE No.2

\begin{tabular}{lcc}
\multicolumn{1}{c}{ Factor } & High & Low \\
\hline Speed $(\mathrm{rpm})$ & 710 & 500 \\
Feed rate $(\mathrm{mm} / \mathrm{min})$ & 315 & 224 \\
Depth of cut $(\mathrm{mm})$ & 3 & 2 \\
\hline
\end{tabular}

Procedures no. 3: As general factorial design was used for identifying the optimum surface roughness with the allocated speed of 3 levels: 500, 710 and 1,000 rpm; the allocated feed rate classified into 3 levels: 160, 224 and $315 \mathrm{~mm} / \mathrm{min}$.
Furthermore, the depth of cut was stable at $2 \mathrm{~mm}$ which did not affect the surface roughness from the second procedure. The findings were as shown in Table II.

TABLE II: THE ALLOCATED VARIATION IN PROCEDURE NO. 3

\begin{tabular}{lccc}
\hline \multicolumn{1}{c}{ Factor } & Level 1 & Level 2 & Level 3 \\
\hline Speed $(\mathrm{rpm})$ & 1,000 & 710 & 500 \\
Feed rate $(\mathrm{mm} / \mathrm{min})$ & 315 & 224 & 160 \\
Depth of cut $(\mathrm{mm})$ & 2 & 2 & 2 \\
\hline
\end{tabular}

Procedure no. 4: To take the real treatment in order to confirm the results. This treatment was tried out to confirm the conformation of each treatment by using a linear equation of procedure no. 3 to predict the surface roughness. Condition was sampling selected with 10 times of a replication without margin errors lower than $5 \%$.

\section{RESUlts}

Results of sampling sizes, the statistic values used in data analysis were reliability at $95 \%$ or significance at $5 \%$. The feed rate was at $315 \mathrm{~mm} / \mathrm{min}$; the speed was $710 \mathrm{rpm}$; the depth of cut was at $2 \mathrm{~mm}$. The twelve repeated treatments revealed that the mean average of surface roughness was at $0.38 \mu \mathrm{m}$ and the standard deviation was $0.07 \mu \mathrm{m}$. Furthermore, the result of sample size investigation was a 5 sampled size.

According to procedure no. 2, the analysis of the variance of surface roughness $\mathrm{R}^{2}$ was of $78.02 \%$ and the Adjust $\mathrm{R}^{2}$ was of $73.21 \%$. This meant that the data variance value was at $100 \mu \mathrm{m}^{2}$. For the variance value at $78.02 \mu \mathrm{m}^{2}$ could be explained with regression model and the remaining value was not explainable due to the uncontrollable variables.

The details are as follows: it is obviously seen that the most variance of surface roughness is implied as a regression model. This can be said that the design of each treatment is appropriate and accurate as shown in Table III.

Table III and Fig. 2 reveal that the main factors affecting the surface roughness of nodular cast iron FCD 400 are feed rate and speed with tendency of higher surface roughness when feed rate increase from 224 to $315 \mathrm{~mm} / \mathrm{min}$ and the speed decrease from 710 to $500 \mathrm{rpm}$ respectively. The surface roughness reduced when the feed rate decreases and the increase speed decreases the surface roughness of nodular cast iron FCD 400 as shown in Fig. 1 and Table III shows that no interaction factors affect the surface roughness.

TABLE III: ANALYSIS OF VARIANCE RESULTS OF SURFACE ROUGHNESS VALUES

\begin{tabular}{|c|c|c|c|c|c|c|}
\hline \multicolumn{7}{|c|}{ Analysis of Variance for Ra, using Adjusted SS for Tests } \\
\hline Source & DF & Seq SS & Adj SS & Adj MS & $\mathrm{F}$ & $\mathrm{P}$ \\
\hline Speed & 1 & 0.230584 & 0.230584 & 0.230584 & 74.86 & 0.000 \\
\hline Feed rate & 1 & 0.076126 & 0.076126 & 0.076126 & 24.71 & 0.000 \\
\hline Depth of cut & 1 & 0.010791 & 0.010791 & 0.010791 & 3.50 & 0.070 \\
\hline Speed $*$ Feed rate & 1 & 0.011594 & 0.011594 & 0.011594 & 3.76 & 0.061 \\
\hline Speed $*$ Depth of cut & 1 & 0.002481 & 0.002481 & 0.002481 & 0.81 & 0.376 \\
\hline Feed Rate ${ }^{*}$ Depth of cut & 1 & 0.011056 & 0.011056 & 0.011056 & 3.59 & 0.067 \\
\hline Speed $*$ Feed rate $*$ Depth of cut & 1 & 0.007209 & 0.007209 & 0.007209 & 2.34 & 0.136 \\
\hline Error & 32 & 0.098570 & 0.098570 & 0.098570 & & \\
\hline Total & 39 & 0.203718 & & & & \\
\hline
\end{tabular}




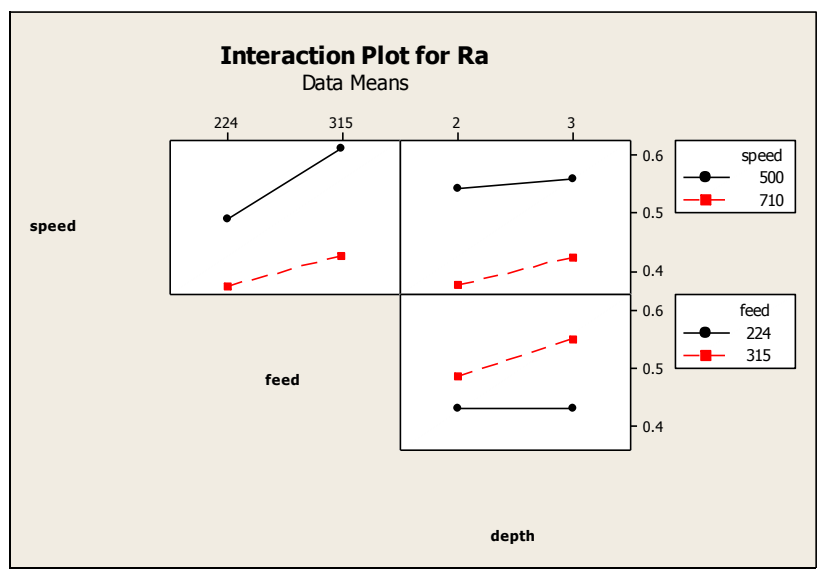

Fig. 1. The interaction effects plot of surface roughness

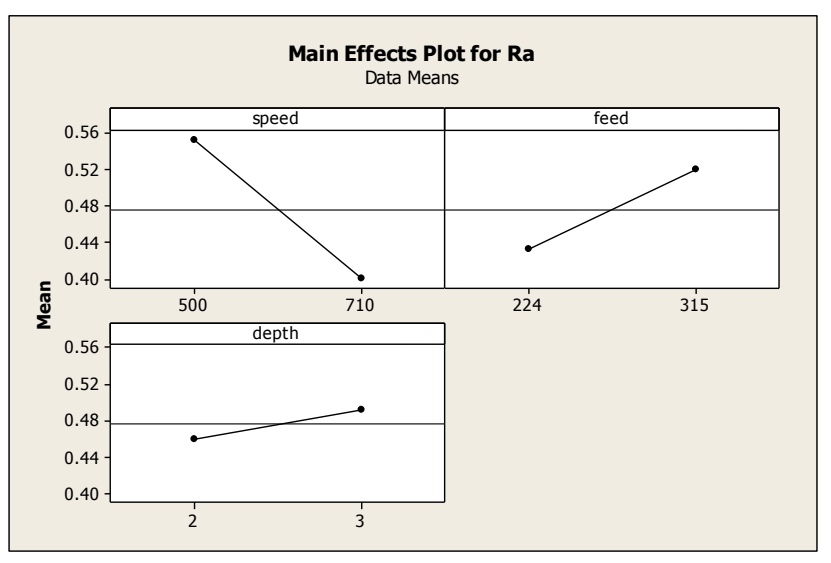

Fig. 2. The main effects plot of surface roughness
Based on procedure no. 3, and data analysis in order to identify the variation of surface roughness of nodular cast iron FCD 400 and adjust for variance analysis. The findings revealed that the designing surface roughness measurement was decision making coefficient of $74.24 \%$ and Adjust $\mathrm{R}^{2}$ was of $69.66 \%$. This meant that the variance value was at 100 $\mu \mathrm{m}^{2}$ and $74.24 \mu \mathrm{m}^{2}$ was implied by the regression model and the rest of data could not be interpreted because of the uncontrolled variable.

Therefore, the data variance to measure the surface roughness could be implied from the feed rate and speed. These brought about the accurate designing treatment and appropriate for data analysis. The analysis of variance for surface roughness $\left(R_{a}\right)$ is shown in Table IV.

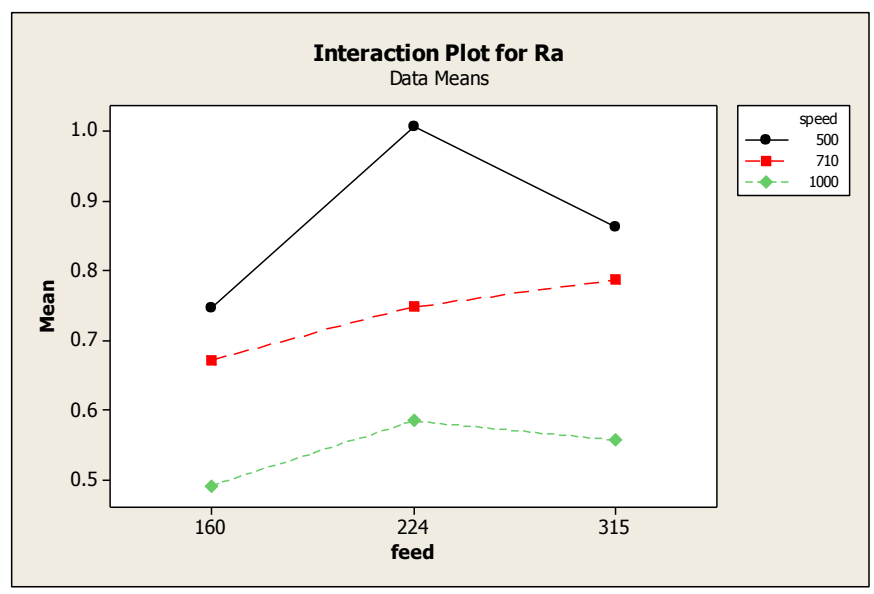

Fig. 3. The interaction effects plot of surface roughness

TABLE IV: ANALYSIS RESULTS OF SURFACE ROUGHNESS VALUES

\begin{tabular}{|c|c|c|c|c|c|c|}
\hline \multicolumn{7}{|c|}{ Analysis of Variance for Ra, using Adjusted SS for Tests } \\
\hline Source & DF & Seq SS & Adj SS & Adj MS & $\mathrm{F}$ & $\mathrm{P}$ \\
\hline Speed & 2 & 0.97382 & 0.97382 & 0.48691 & 50.72 & 0.000 \\
\hline Feed rate & 2 & 0.19285 & 0.19285 & 0.09642 & 10.04 & 0.000 \\
\hline Speed $*$ Feed rate & 4 & 0.07843 & 0.07843 & 0.01961 & 2.04 & 0.104 \\
\hline Error & 45 & 0.43204 & 0.43204 & 0.00960 & & \\
\hline Total & 53 & 1.67713 & & & & \\
\hline
\end{tabular}

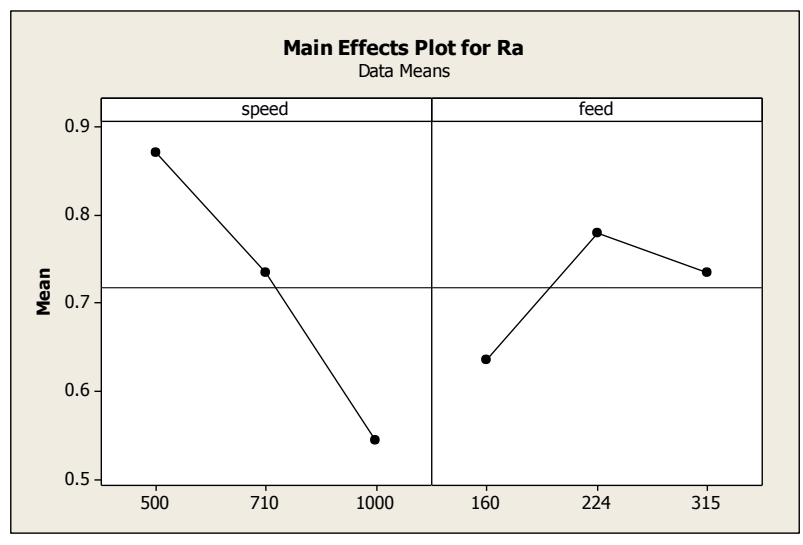

Fig. 4. The main effects plot of surface roughness

The result of this treatment shown in Table IV, Fig. 3 and Fig. 4 presents that the main factors influencing the surface roughness of nodular cast iron FCD 400 are feed rate and speed. The surface roughness reduces when the feed rate decreases and the decreased speed increases the surface roughness of nodular cast iron FCD 400 as shown in Table IV and Fig. 4. The other factors do not have effects on the surface roughness.

The regression analysis of the surface roughness of nodular cast iron FCD 400, and feed rate and speed by adjusting the variation. The ratio of feed rate is classified into 3 levels: 160, 224 and $315 \mathrm{~mm} / \mathrm{min}$; the speed is set into 3 levels: 500, 710 and 1,000 rpm. Further, the depth of cut stable at $2 \mathrm{~mm}$. The recessive test is Program Minitab R.15. The findings are shown in Table $\mathrm{V}$.

The analysis of regression model can be related to the main factors and the surface roughness $\left(\mathrm{R}_{\mathrm{a}}\right)$ as shown in this linear eq. 1.

$$
R_{a}=1.07-0.000655 \text { speed }+0.000562 \text { feed rate }
$$

The result of procedure no. 4 is confirming all treatments by using an algebraic equation to predict the surface roughness of nodular cast iron FCD 400. The sampling of cutting process within the limited area can be compared to the 
real means. The deviation lessens than $5 \%$. From the experiment is to confirm the result of a comparison between the equation and the percent accuracy with the margin of error The result from the experiment of mean absolute percentage error (MAPE) of the equation of surface roughness is $3.50 \%$ which is less than the margin of error and is acceptable.

Analysis of the wear of cutting tool by Stereo microscope the condition of the speed $710 \mathrm{rpm}$, feed rate $224 \mathrm{~mm} / \mathrm{min}$. And depth of cut $2 \mathrm{~mm}$ wear, it was similar to Flank Wear is cutting edge on the work piece. The front edge and sides of the wear is shown in Fig. 5.

TABLE V: REgRESSION ANALYSIS: SURFACE Roughness VALUES, SPEED AND FEED RATE

\begin{tabular}{|c|c|c|c|c|}
\hline \multicolumn{5}{|c|}{ Regression Analysis: Ra versus Speed, Feed } \\
\hline \multicolumn{5}{|c|}{$\begin{array}{l}\text { The regression equation is } \mathrm{Ra}=1.07-0.000655 \text { speed }+0.000562 \mathrm{feed} \\
\text { rate }\end{array}$} \\
\hline Predictor & Coef & SE Coef & $\mathrm{T}$ & $\mathrm{P}$ \\
\hline Constant & 1.06866 & 0.07936 & 13.47 & 0.000 \\
\hline Speed & -0.00065508 & 0.00007404 & -8.85 & 0.000 \\
\hline Feed rate & 0.0005615 & 0.0002387 & 2.35 & 0.023 \\
\hline \multicolumn{5}{|c|}{$\mathrm{S}=0.111538 \mathrm{R}-\mathrm{Sq}=62.2 \% \mathrm{R}-\mathrm{Sq}(\mathrm{adj})=60.7 \%$} \\
\hline
\end{tabular}

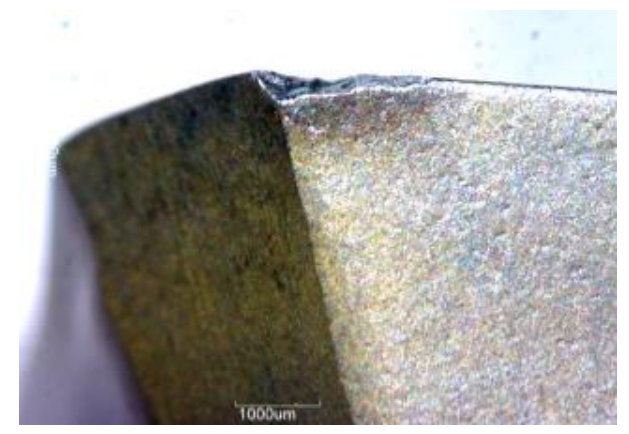

Fig. 5. The wear of Cutting tool.

\section{CONCLUSION}

The study of investigating the surface roughness in nodular cast iron FCD 400 face milling process by milling machine and using face mill cutting tool with 5 edges in order to identify the means of the surface roughness of nodular cast iron FCD 400 face milling process in part mold and part automotive production. It could be concluded as following;

1) Cutting speed significantly effects the surface roughness of nodular cast iron FCD 400 followed by speed and feed rate. The result also indicates that higher value of speed and lower feed rate tended to decrease the surface roughness.

2) The linear equation in this research was as follows: $R_{a}=$ $1.07-0.000655$ speed +0.000562 feed rate. This equation could be applied with face mill cutting tool with 5 edges speed was at $500-1,000 \mathrm{rpm}$ and the feed rate at $160-315 \mathrm{~mm} / \mathrm{min}$.

3 ) When comparing the treatment for confirming the results to the findings using the formulation displayed, the measurement was $5 \%$ of errors. The mean absolute percentage error (MAPE) was of $3.50 \%$ fewer than the margin of error that could be acceptable.

\section{ACKNOWLEDGMENT}

The authors would like to thank the Faculty of Engineering, Rajamangala University of Technology Srivijaya (RMUTSV) for financial support and thank the staff of machining laboratory, Department of Industrial Engineering, Faculty of Engineering, For supporting to using various kinds of practical machine in conducting this research.

\section{REFERENCES}

[1] A. K. Ghani, I. Choudhury, and A. Husni, "Study of tool life, surface roughness and vibration in machining nodular cast iron with ceramic tool," J. Mater Process Technol, vol. 127, pp. 17-22, 2002.

[2] Y. M. Ertekin, Y. Kwon, and T. L. Tseng, "Identification of common sensory features for the control of CNC milling operations under varying cutting conditions," International Journal of Machine Tools and Manufacture, vol. 43, no. 9, pp. 897-904, 2003.

[3] P. G. Bernados and G. C. Vosniakos, "Prediction of surface roughness in CNC face milling using neural networks and Taguchi's design of experiments," Robotic and Computer Integrated Manufacturing, vol. 18, no. 5-6, pp. 343-354, 2002.

[4] M. Y. Wang and H. Y. Chang, "Experimental study of surface roughness in slot end milling AL2014-T6," International Journal of Machine Tools and Manufacture, vol. 44, no. 1, pp. 51-57, 2004.

[5] W. Wang, S. H. Kweon, and S. H. Yang, "A study on roughness of the micro-end-milled surface produced by a miniatured machine," Journal of Materials Processing Technology, vol. 162-163, pp. 702-708, 2005.

[6] H. Oktem, T. Erzurumlu, and H. Kurtaran, "Application of response surface methodology in the optimization of cutting conditions for surface roughness," Journal of Materials Processing Technology, vol. 170 , no. $1-2$, pp. $11-16,2005$.

[7] N. S. K. Reddy and P. V. Rao, "Selection of optimum tool geometry and cutting conditions using surface roughness prediction model for end milling," Int. J. Adv. Manuf. Technol, vol. 26, no. 11-12, pp. 1202-1210, 2005

[8] B. Ozcelik and M. Bayramoglu, "The statistical modeling of surface roughness in high speed flat end milling," International Journal of Machine Tools and Manufacture, vol. 46, no. 12-13, pp. 1395-1402, 2006.

[9] E. Bagci and S. Aykut, "A study of Taguchi optimization method for identifying optimum surface roughness in CNC face milling of cobalt-based alloy (satellite 6)," Int. J. Adv. Manuf. Technol, vol. 29, no. 9-10, pp. 940-947, 2006.

[10] C. K. Chang and H. S. Lu, "Design optimization of cutting parameters for side milling operations with multiple performance characteristics," Int. J. Adv. Manuf. Technol, vol. 32, no. 1-2, pp. 18-26, 2007.

[11] D. C. Montgomery, Design and analysis of experiments. 6th ed. john Wiley \& Son, inc., 2005, New York.

[12] K. Ploypanichjaroen, Engineering statistics Volume 2. Minitab processed. 4th ed, Technology Promotion Association (Thai-Japanese), 2003, Bangkok.

[13] P. Sutus Na Ayuthaya and P. Luengpaiboon, Design and analysis of experiment. Top publishing Co., Ltd., 2008, Bangkok.

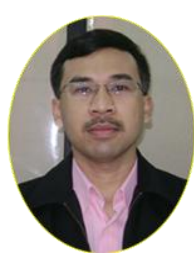

Surasit Rawangwong is an assistant professor in Department of Industrial Engineering, Faculty of Engineering Rajamangala University of Technology Srivijaya, Songkhla, Thailand. He received a M.Eng from Manufacturing System Engineering, Faculty of Engineering at King Mongkut's University of Technology Thonburi in 2002. His research interests include Design of Experiment, Manufacturing Processes, Production Technology, Quality Control, Ergonomics and Productivity.

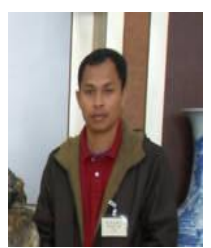

Jaknarin Chatthong is a lecturer in Department of Industrial Engineering, Faculty of Engineering Rajamangala University of Technology Srivijaya, Songkhla, Thailand. He received a M.Eng from Production Engineering, Faculty of Engineering at King Mongkut's University of Technology Bangkok in 2004. His research interests include Machine Design, Manufacturing Processes, Productivity. 


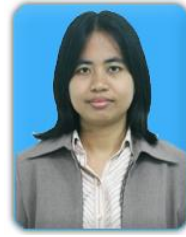

Julaluk Rodjananugoon is a lecturer in Departmen of Industrial Engineering, Faculty of Engineering Rajamangala University of Technology Srivijaya, Songkhla, Thailand. She received a M.Eng from Industrial Engineering, Faculty of Engineering at at Prince of Songkhla University in 2007. Her research interests include Design of Experiment, Manufacturing Processes, Productivity.

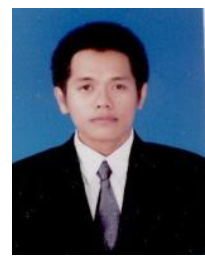

Worapong Boonchouytan is a lecturer in Department of Industrial Engineering, Faculty of Engineering Rajamangala University of Technology Srivijaya, Songkhla, Thailand. He received a M.Eng from Industrial and System Engineering, Faculty of Engineering at Prince of Songkhla University in 2010. His research interests include Design of Experiment, Manufacturing Processes, Welding Engineering.

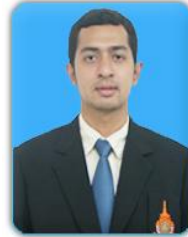

Rommdon Burapa is a lecturer in Department of Industrial Engineering, Faculty of Engineering Rajamangala University of Technology Srivijaya, Songkhla, Thailand. He received a M.Eng from Materials Engineering, Faculty of Engineering a Prince of Songkhla University in 2009. His research interests include Manufacturing Processes, Semi-Solid Metal, Materials Engineering, Casting Technology. 